\title{
Editorial
}

\section{Un chant distinct ...}

Ce n'est pas sans un sentiment de fierté et de reconnaissance que je présente ce numéro spécial de LittéRéalité consacré à la poésie contemporaine au Québec. Reconnaissant, je le suis surtout envers les poètes dont les textes inédits, contribués si genéreusement, recèlent la fraîcheur, la vigueur et l'attrait du nouveau. L'ensemble constitue une petite anthologie —une variété de vers lyriques, de fragments épiques, d'odes, de fables, de poèmes en prose...- où l'on peut percevoir l'état actuel de la poésie au Québec.

Dans son recueil Poésie du Québec (1962), après avoir constaté l'inévitable désintégration des formes, Alain Bosquet regrette que la plus grande partie de la jeune poésie ne chante plus. Le refus total avait-il enfermé le poète dans un narcissisme boudeur, violent et stérile? Quelle distance de la proclamation de l'abbé Nantel dans Les Fleurs de la poésie canadienne (1911): "La poésie vient de Dieu et va à Dieu." L'éloignement d'un idéal poétique, ou bien social, avait-il arrêté l'élan vital de la poésie? L'aspect formel désintégré serait donc une image de l'âme aride, craquelée, sans souffle, sans voix... sans chant.

Pourtant, dans son anthologie Poètes du Québec (1969), Jacques Cotnam reconnaît dans cette poésie une vitalité qui lui a permis de franchir les frontières et d'être appréciée hors du Québec. En fait, une vingtaine d'années plus tard, cette poésie qui s'est ouverte et qui parle au monde, affranchie et enrichie de cette nouvelle vision globale, manifeste pleinement sa confiance et son essor. Le visage poétique du Québec se dessine plus clairement; sa voix se reconnaît plus facilement par son chant distinct. La poésie québécoise contemporaine chante la liberté et l'amour; elle chante la femme et la vie illimitée; et elle chante la nuit, le lac, le vent boréal, la neige neuve et la terre, Miguasha et Massawipi. Cette jeune poésie n'a pas oublié son héritage esthétique et culturel; c'est ainsi qu'en tête de ce recueil il est juste de la relier à la "Libération" de l'immortel Grandbois.

Il est regrettable que le mythe d'un langage hermétique, inaccessible persiste toujours. La poésie demeure un art pour les happy few; elle vit dans les revues académiques et sa voix rythmée 
et imagée s'entend parfois dans les salles de cours universitaires. En général, les charmes de la Muse sont devenus effrayants. Il faudra d'immenses efforts de communication pour dissiper ce mythe et, enfin, pour faire entrer la poésie dans nos écoles, dans nos foyers et dans le coeur de tout un peuple... aussi aisément qu' un conte de fee. Notre voeux: que ces pages renfermant cette voix auguste qui parle le langage universel de l'amour et de la beaute-ce "Saint Langage," dit Paul Valéry - franchissent tout obstacle et toute frontière pour créer des liens indéliables. "Le poéme," écrit Francois Charron, "est le lieu vrai du monde."

Sergio Villani (Université York)

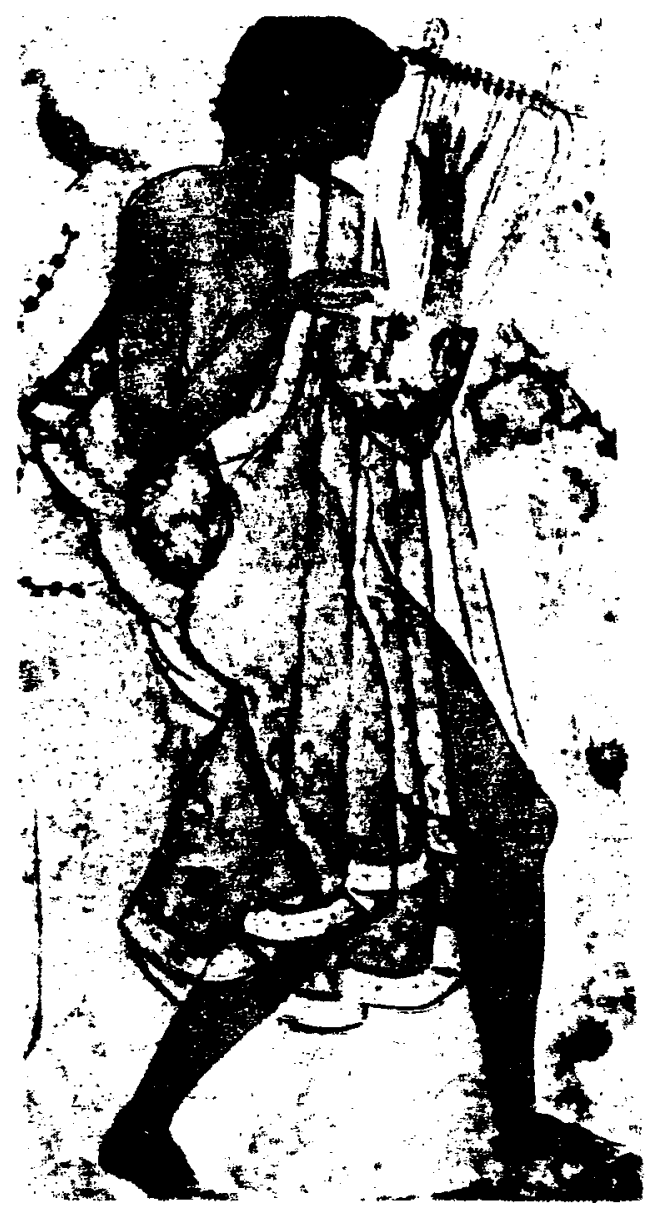

